\title{
Community predictors of school engagement: the role of families and youth-adult partnership in Malaysia
}

\begin{abstract}
School engagement is central to students' academic achievement and their successful transition into post-secondary programs. Existing research on contributors to school engagement has been mostly limited to individual and school-based predictors in Western countries. Additionally, few studies have investigated the 'cross-over' relationship between student experiences within community settings and school engagement. This study addresses these limitations. It explores youth-adult partnership (youth voice, supportive adult relationships) in two types of out-of-school time youth programs and family processes (parental monitoring, family cohesion) as predictors of cognitive and emotional school engagement in Malaysia. Surveys were administered to 507 diverse students (56\% male, 64\% Malay) age 15 to 17 , attending after-school co-curricular and community-based youth programs. The findings indicate that experiences in community and family settings may have a positive influence on student experiences in school. Specifically, OLS hierarchical regression analysis showed that youth voice in decision-making within both types of programs as well as parental monitoring contributed to both types of school engagement. Supportive relationships with adult staff were significantly associated with students' emotional engagement. Implications for practice in out-of-school time programs and schools, as well as future research, are discussed.
\end{abstract}

Keyword: Youth-adult partnership; School engagement; Youth voice; Parental monitoring; Family cohesion; Malaysia; Supportive adult relationships 